\title{
The Calculation of the Nominal Data of a Turbine Blade with the Use of CAD Software
}

\author{
Marek Magdziak ${ }^{1, a}$ \\ ${ }^{1}$ Rzeszow University of Technology, The Faculty of Mechanical Engineering and Aeronautics, \\ Department of Manufacturing Techniques and Automation, al. Powstańców Warszawy 8, 35-959 Rzeszów, Poland
}

\begin{abstract}
In the article there was presented the comparison of the nominal data of a selected turbine blade which were calculated by using of both the measurement software Blade Pro - cooperating with, for example, coordinate measuring machines - and the computer aided design software CATIA. The comparison of the nominal data of the chosen workpiece was conducted in order to perform the analysis of the possibility of using the software CATIA in the case of the measurement application which is usually conducted by means of the coordinate measuring technique. The nominal data in the case of the two analyzed software packages concern the selected measurement characteristics of a turbine blade. The correct calculations of the nominal data have direct influence on the results of the real coordinate measurements of a turbine blade.
\end{abstract}

\section{Introduction}

The coordinate measuring technique can be used in the case of the coordinate measurements of the products which are characterized by various degrees of geometrical complexity. The example of the product measured by means of the coordinate measuring technique is a turbine blade, which is the object composed of free-form surfaces. The curvilinear surfaces of products can be measured with the use of the various coordinate measuring systems, e.g. coordinate measuring machines (CMMs) equipped with both contact and noncontact measurement probes, the measuring systems based on the laser triangulation, the photogrammetry and the computer tomography.

The coordinate measurements of a turbine blade can be realized with the use of coordinate measuring machines cooperating with the measurement software Calypso and Blade Pro produced by the Carl Zeiss company. The measurement software Blade Pro is used for the detailed analysis of the results of coordinate measurements of a turbine blade. The software Blade Pro uses the measurement data gained by using of the software Calypso. The data exchange between the measurement software Calypso and Blade Pro is performed automatically by means of the appropriate macro available in the measurement software Calypso. In order to perform the coordinate measurements of a turbine blade and the analysis of gained measurement data the user of the software Calypso should use one of the following measurement elements: curve $2 D$ or curve $3 D$.

The above mentioned measurement elements differ in the way of the orientation of the normal vectors to free- form curves at their nominal points and the possibility of the distribution of nominal points along considered measured curves. In the case of the measurement element curve $3 D$ nominal points can be distributed nonuniformly. The non-uniform distribution is based on the curvature of the profile along which coordinate measurements are conducted. In the case of the measurement element curve $2 D$ nominal points can be distributed uniformly along considered free-form curves [1]. The selection of the appropriate measurement element should be based on the assessment of the shape of a measured object. For example in the case of the turbine blade with the small change of curvature along its axis there can be used the measurement element curve $2 D$. This element does not take into account the shape of a measured product around a measured profile.

The accuracy of the coordinate measurements of freeform surfaces of products depends on many factors, e.g. the geometrical accuracy of a used coordinate measuring machine and the accuracy of the algorithms included in the metrological software which cooperates with coordinate measuring systems. The measurement software of measuring systems may include, for example, the various methods of probe radius correction process used in order to calculate the coordinates of corrected measured points $[2,3]$, the different algorithms of the distribution of points [4-6] or the various methods of the best fit of measured data to nominal one [7].

In the paper there was presented the analysis of the accuracy of the calculation of nominal data in the case of the coordinate measurements of a turbine blade. The analysis was done with the use of the measurement software Blade Pro and the CAD software CATIA. The 
analysis was performed in order to asses the possibilities of using the selected computer aided design software in the case of the measurement task which is usually conducted by means of the coordinate measuring technique. The software CATIA is commonly used at the different stages of the design process of products and it is more popular than the measurement software Blade Pro. The comparison of the nominal data, gained by using of the above mentioned software, was conducted for the selected measurement characteristics of a turbine blade.

\section{Numerical Investigations}

Numerical research concerned the coordinate measurements of a turbine blade. It was done in order to compare the nominal data of the considered object. Two groups of the nominal data were gained by using of the software Blade Pro and CATIA. The data calculated using the measurement software Blade Pro were used as the reference one. The software Blade Pro is specialized in the field of the assessment of the accuracy of a turbine blade. The main purpose was to check whether the commonly used CAD software CATIA enables computing measurement characteristics based on measurement data and what are the differences between the nominal data obtained with the CATIA and the Blade Pro. The differences between the nominal data calculated using two considered software packages affect the results of real coordinate measurements of a turbine blade. The comparison of the nominal data was done for six selected, uniformly distributed cross-sections of the turbine blade (A-A - F-F) (refer with: Fig. 1).

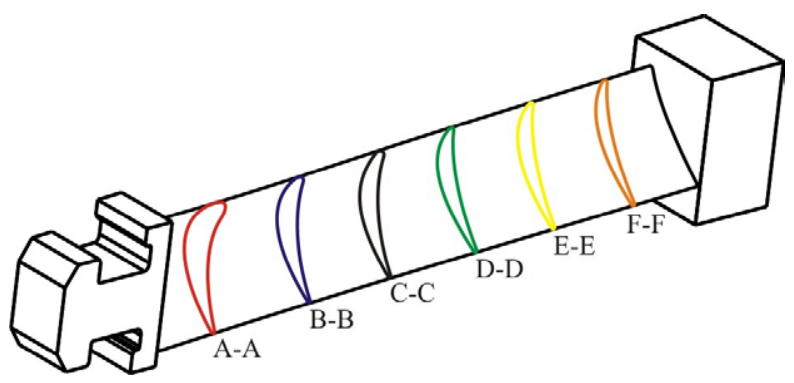

Figure 1. The view of a turbine blade used for the investigations

During numerical investigations there was used the measurement element curve $2 D$. Therefore, the nominal points were distributed uniformly along the free-form curves, which represent the shape of considered workpiece. There were used approximately 1000 nominal points in each analyzed cross-section of the turbine blade. The analyzed measurement characteristics in the software Blade Pro and CATIA were the following:

- the maximum thickness (denoted as A),

- the maximum length (B),

- the length of mean camber line (C),

- the length of profile chord (D),

- the angle of profile chord (E),

- the angle of tangent line $(\mathrm{F})$,

- the surface area $(\mathrm{G})$
The selected analyzed geometrical and measurement characteristics of the turbine blade are visualized in the Fig. 2. In the case of the first and the second measurement characteristics (A and B) there were performed the optimization processes by using of the software CATIA. The optimization criterion was the maximum value of an objective function. The objective functions in the optimization processes were the maximum lengths and the maximum thicknesses in all considered cross-sections of the analyzed turbine blade.

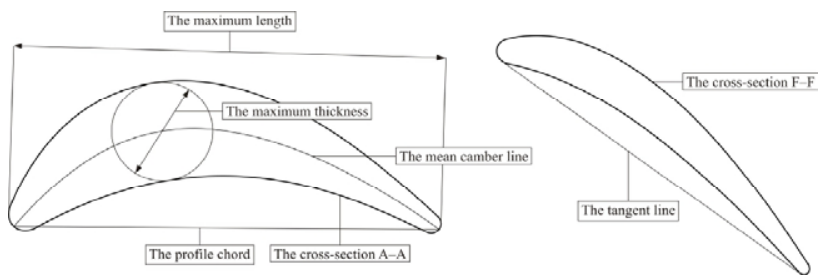

Figure 2. The selected analyzed characteristics of the turbine blade

The software CATIA enables, among others, the use of the following algorithms of an optimization process: the simulated annealing algorithm (denoted as M1) and the gradient algorithm without constraint (M2) (refer with: Fig. 3). The optimization algorithms are available in the module Product Engineering Optimizer of the software CATIA.

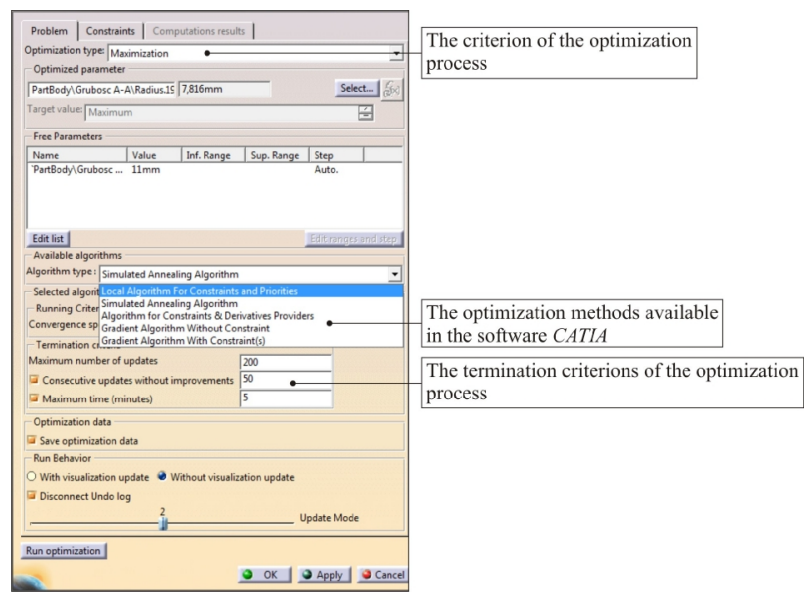

Figure 3. The optimization methods and the optimization settings available in the CAD software CATIA

The termination criterions of the optimization processes were the following: the maximum number of iterations, the maximum number of iterations without the improvement in the case of the value of the objective function and the maximum time of performed calculations. The maximum number of iterations was equal 200, the maximum number of iterations with no improvement was equal 50 and the maximum time of the optimization process was equal 5 minutes. In the case of the measurement software Blade Pro there was not used any filtering of nominal points. The filtering process was not applied because the computer aided design software CATIA has not such capability. 
The nominal data of the analyzed measurement characteristics calculated by means of the software Blade Pro are presented in the Table 1 . In the case of using the software CATIA the computed nominal data are shown in the Table 2.

Table 1. The nominal data of the analyzed turbine blade calculated by using of the software Blade Pro

\begin{tabular}{|c|c|c|c|c|c|c|}
\hline \multirow{2}{*}{\begin{tabular}{|c|} 
The \\
measurement \\
characteristic \\
of the turbine \\
blade \\
\end{tabular}} & \multicolumn{6}{|c|}{ The cross-section of the turbine blade } \\
\hline & $\mathrm{A}-\mathrm{A}$ & B-B & $\mathrm{C}-\mathrm{C}$ & D-D & $\mathrm{E}-\mathrm{E}$ & $\mathrm{F}-\mathrm{F}$ \\
\hline A & $\begin{array}{c}15,636 \\
\mathrm{~mm}\end{array}$ & $\begin{array}{c}13,730 \\
\mathrm{~mm}\end{array}$ & $\begin{array}{c}11,801 \\
\mathrm{~mm}\end{array}$ & $\begin{array}{c}9,941 \\
\mathrm{~mm}\end{array}$ & $\begin{array}{c}8,277 \\
\mathrm{~mm}\end{array}$ & $\begin{array}{c}6,916 \\
\mathrm{~mm}\end{array}$ \\
\hline B & $\begin{array}{c}66,693 \\
\mathrm{~mm}\end{array}$ & $\begin{array}{c}62,932 \\
\mathrm{~mm}\end{array}$ & $\begin{array}{c}60,738 \\
\mathrm{~mm}\end{array}$ & $\begin{array}{c}59,660 \\
\mathrm{~mm}\end{array}$ & $\begin{array}{c}59,403 \\
\mathrm{~mm}\end{array}$ & $\begin{array}{c}59,865 \\
\mathrm{~mm}\end{array}$ \\
\hline $\mathrm{C}$ & $\begin{array}{c}74,637 \\
\mathrm{~mm}\end{array}$ & $\begin{array}{c}69,737 \\
\mathrm{~mm}\end{array}$ & $\begin{array}{c}66,194 \\
\mathrm{~mm}\end{array}$ & $\begin{array}{c}63,766 \\
\mathrm{~mm}\end{array}$ & $\begin{array}{c}62,321 \\
\mathrm{~mm}\end{array}$ & $\begin{array}{c}61,833 \\
\mathrm{~mm}\end{array}$ \\
\hline D & $\begin{array}{c}65,554 \\
\mathrm{~mm}\end{array}$ & $\begin{array}{c}62,116 \\
\mathrm{~mm}\end{array}$ & $\begin{array}{c}60,038 \\
\mathrm{~mm}\end{array}$ & $\begin{array}{c}59,027 \\
\mathrm{~mm}\end{array}$ & $\begin{array}{c}58,809 \\
\mathrm{~mm}\end{array}$ & $\begin{array}{c}59,450 \\
\mathrm{~mm}\end{array}$ \\
\hline E & $\begin{array}{c}0,327 \\
\text { deg }\end{array}$ & $\begin{array}{c}7,909 \\
\text { deg }\end{array}$ & $\begin{array}{c}15,519 \\
\operatorname{deg}\end{array}$ & $\begin{array}{c}22,903 \\
\text { deg }\end{array}$ & $\begin{array}{c}29,787 \\
\text { deg }\end{array}$ & $\begin{array}{c}36,258 \\
\operatorname{deg}\end{array}$ \\
\hline $\mathrm{F}$ & $\begin{array}{c}0,377 \\
\text { deg }\end{array}$ & $\begin{array}{c}7,988 \\
\text { deg }\end{array}$ & $\begin{array}{c}15,589 \\
\text { deg }\end{array}$ & $\begin{array}{c}22,922 \\
\text { deg }\end{array}$ & $\begin{array}{c}29,793 \\
\text { deg }\end{array}$ & $\begin{array}{c}36,163 \\
\text { deg }\end{array}$ \\
\hline G & $\begin{array}{c}777,308 \\
\mathrm{~mm}^{2}\end{array}$ & $\begin{array}{c}536,988 \\
\mathrm{~mm}^{2}\end{array}$ & $\begin{array}{c}527,516 \\
\mathrm{~mm}^{2}\end{array}$ & $\begin{array}{c}439,619 \\
\mathrm{~mm}^{2}\end{array}$ & $\begin{array}{c}369,777 \\
\mathrm{~mm}^{2}\end{array}$ & $\begin{array}{c}314,500 \\
\mathrm{~mm}^{2}\end{array}$ \\
\hline
\end{tabular}

Table 2. The nominal data of the analyzed turbine blade calculated by using of the software CATIA

\begin{tabular}{|c|c|c|c|c|c|c|}
\hline $\begin{array}{c}\text { The } \\
\text { measurement } \\
\text { characteristic } \\
\text { of the turbine } \\
\text { blade }\end{array}$ & A-A & B-B & C-C & D-D & E-E & F-F \\
\cline { 2 - 7 } A & $\begin{array}{c}15,636 \\
\mathrm{~mm}\end{array}$ & $\begin{array}{c}13,730 \\
\mathrm{~mm}\end{array}$ & $\begin{array}{c}11,801 \\
\mathrm{~mm}\end{array}$ & $\begin{array}{c}9,941 \\
\mathrm{~mm}\end{array}$ & $\begin{array}{c}8,277 \\
\mathrm{~mm}\end{array}$ & $\begin{array}{c}6,916 \\
\mathrm{~mm}\end{array}$ \\
\hline B & $\begin{array}{c}66,693 \\
\mathrm{~mm}\end{array}$ & $\begin{array}{c}62,932 \\
\mathrm{~mm}\end{array}$ & $\begin{array}{c}60,739 \\
\mathrm{~mm}\end{array}$ & $\begin{array}{c}59,661 \\
\mathrm{~mm}\end{array}$ & $\begin{array}{c}59,404 \\
\mathrm{~mm}\end{array}$ & $\begin{array}{c}59,865 \\
\mathrm{~mm}\end{array}$ \\
\hline C & $\begin{array}{c}74,635 \\
\mathrm{~mm}\end{array}$ & $\begin{array}{c}69,741 \\
\mathrm{~mm}\end{array}$ & $\begin{array}{c}66,195 \\
\mathrm{~mm}\end{array}$ & $\begin{array}{c}63,768 \\
\mathrm{~mm}\end{array}$ & $\begin{array}{c}62,321 \\
\mathrm{~mm}\end{array}$ & $\begin{array}{c}61,832 \\
\mathrm{~mm}\end{array}$ \\
\hline $\mathrm{D}$ & $\begin{array}{c}65,556 \\
\mathrm{~mm}\end{array}$ & $\begin{array}{c}62,268 \\
\mathrm{~mm}\end{array}$ & $\begin{array}{c}60,114 \\
\mathrm{~mm}\end{array}$ & $\begin{array}{c}59,072 \\
\mathrm{~mm}\end{array}$ & $\begin{array}{c}58,814 \\
\mathrm{~mm}\end{array}$ & $\begin{array}{c}59,442 \\
\mathrm{~mm}\end{array}$ \\
\hline E & $\begin{array}{c}0,349 \\
\mathrm{deg}\end{array}$ & $\begin{array}{c}8,055 \\
\mathrm{deg}\end{array}$ & $\begin{array}{c}15,590 \\
\mathrm{deg}\end{array}$ & $\begin{array}{c}22,953 \\
\mathrm{deg}\end{array}$ & $\begin{array}{c}29,794 \\
\mathrm{deg}\end{array}$ & $\begin{array}{c}36,250 \\
\mathrm{deg}\end{array}$ \\
\hline F & $\begin{array}{c}0,377 \\
\mathrm{deg}\end{array}$ & $\begin{array}{c}7,990 \\
\mathrm{deg}\end{array}$ & $\begin{array}{c}15,591 \\
\mathrm{deg}\end{array}$ & $\begin{array}{c}22,922 \\
\mathrm{deg}\end{array}$ & $\begin{array}{c}29,794 \\
\mathrm{deg}\end{array}$ & $\begin{array}{c}36,163 \\
\mathrm{deg}\end{array}$ \\
\hline G & $\begin{array}{c}777,312 \\
\mathrm{~mm}\end{array}$ & $\begin{array}{c}636,987 \\
\mathrm{~mm}\end{array}$ & $\begin{array}{c}527,543 \\
\mathrm{~mm}\end{array}$ & $\begin{array}{c}439,589 \\
\mathrm{~mm}\end{array}$ & $\begin{array}{c}369,814 \\
\mathrm{~mm}\end{array}$ & $\begin{array}{c}314,490 \\
\mathrm{~mm}\end{array}$ \\
\hline
\end{tabular}

The comparisons of the results gained when using the selected methods of optimization (M1 and M2) are presented in the Tables 3 and 4. The results concern the number of conducted iterations when searching for the maximum values of the thickness and the length of the considered turbine blade in each analyzed cross-section. The number of iterations is connected with the time of computations.
Table 3. The number of iterations gained by using of the considered optimization methods in the case of the maximum thickness of the turbine blade

\begin{tabular}{|c|c|c|c|c|c|c|}
\hline \multirow{2}{*}{$\begin{array}{c}\text { The } \\
\text { optimization } \\
\text { method }\end{array}$} & \multicolumn{5}{|c|}{ The cross-section of the turbine blade } \\
\cline { 2 - 7 } & A-A & B-B & C-C & D-D & E-E & F-F \\
\hline M1 & 133 & 200 & 172 & 197 & 150 & 200 \\
\hline M2 & 133 & 122 & 117 & 132 & 116 & 118 \\
\hline
\end{tabular}

Table 4. The number of iterations gained by using of the considered optimization methods in the case of the maximum length of the turbine blade

\begin{tabular}{|c|c|c|c|c|c|c|}
\hline \multirow{2}{*}{$\begin{array}{c}\text { The } \\
\text { optimization } \\
\text { method }\end{array}$} & \multicolumn{5}{|c|}{ The cross-section of the turbine blade } \\
\cline { 2 - 7 } & A-A & B-B & C-C & D-D & E-E & F-F \\
\hline M1 & 97 & 174 & 95 & 183 & 178 & 200 \\
\hline M2 & 126 & 130 & 124 & 127 & 123 & 124 \\
\hline
\end{tabular}

\section{Summary}

The analysis of the gained results of the numerical investigations indicates that there are no significant differences between the nominal data in the case of the maximum thickness (A), the maximum length (B) and the angle of tangent line $(\mathrm{F})$, which were calculated by using of the software Blade Pro and CATIA. In the case of the length of mean camber line $(\mathrm{C})$ the biggest difference between two groups of the nominal data was gained for the cross-section B-B of the analyzed turbine blade. The gained difference may be the result of using the smaller number of the circles inscribed in the considered profile of the turbine blade when using the CAD software CATIA compared to the number of the circles used in the software Blade Pro.

The differences between the nominal data in the field of the length of profile chord (D) and the angle of profile chord (E) may be the result of the way of calculating the points which were used in order to generate the profile chord of the turbine blade. In order to calculate the coordinates of the mentioned points the mean camber line had to be extended by using the Extrapolate function in the software CATIA up to the intersection with the profile of the turbine blade. Moreover, the differences between the values of the length of profile chord (D) and the angle of profile chord (E) may result from the limited number of the data used to calculate the mean camber line in the software CATIA.

The discrepancies between the nominal data concerning the surface area $(G)$ calculated for the analyzed cross-sections may be the result of using the different interpolation methods of the nominal points in the considered software Blade Pro and CATIA. The gained results (refer with: Table 1 and Table 2) show that there is the possibility of using the software CATIA in the case of the real coordinate measurements of the selected measurement characteristics of the turbine blade.

The optimization processes in all cases were performed for the same input data. On the basis of the calculated numbers of iterations when searching for the maximum values of the length and the thickness (refer with: Table 3 and Table 4) better results, in most cases, 
were gained with the use of the gradient algorithm without constraint (M2). Additional investigations should be connected with the analysis of the results of real measurements of the turbine blade.

\section{References}

1. Carl Zeiss, Calypso, Software documentation.

2. A. Kawalec, M. Magdziak: The selection of radius correction method in the case of coordinate measurements of a turbine blade. 11th International Symposium on Measurement and Quality Control, Kraków-Kielce (2013).

3. A. Woźniak, J. R. R. Mayer, M. Bałaziński: Stylus tip envelop method: corrected measured point determination in high definition coordinate metrology. The International Journal of Advanced
Manufacturing Technology, Vol. 42 (2009), pp. 505514.

4. D. F. Elkott, H. A. Elmaraghy, W. H. Elmaraghy: Automatic sampling for CMM inspection planning of free-form surfaces. International Journal of Production Research, Vol. 40 (2002), pp. 2653-2676.

5. D. ElKott: Coordinate metrology of freeform surfaces. A CAD-based, practical approach. VDM Verlag Dr. Müller GmbH \& Co. KG, Saarbrücken (2011).

6. S. O. Obeidat, S. Raman: An intelligent sampling method for inspecting free-form surfaces. The International Journal of Advanced Manufacturing Technology, Vol. 40(2009), pp. 1125-1136.

7. A. Kawalec, M. Magdziak: Wptyw metody dopasowania na wyniki pomiarów pióra topatki. Mechanik,
2
(2013). 